\title{
Uses and limitations of high dose dipyridamole stress echocardiography for evaluation of coronary artery disease
}

Peter Mazeika, Petros Nihoyannopoulos, Jayshree Joshi, Celia M Oakley

\begin{abstract}
Objective-To compare the usefulness of high dose dipyridamole stress echocardiography with dipyridamole stress electrocardiography and exercise electrocardiography for the evaluation of coronary artery disease.

Design-Prospective investigation with coronary angiography as the criterion standard and blinded assessment of study data.

Setting-Cardiology unit of a tertiary referral centre.

Subjects-Fifty eight patients with suspected coronary disease; three of these were excluded because of poor echogenicity at baseline (test feasibility 95\%). Angiography showed normal coronary arteries in 15 and coronary disease ( $\geqslant 70 \%$ diameter stenosis) in 40 .

Interventions-Cross sectional echocardiography and 12 lead electrocardiography during dipyridamole stress (up to $1 \mathrm{mg} / \mathrm{kg}$ ) and exercise electrocardiography on a separate occasion. Wall motion was analysed with an 11segment model developed at Hammersmith Hospital.
\end{abstract}

Main outcome measures-Test sensitivity, specificity, and side effect data.

Results-16 of 40 patients with coronary artery disease had inducible asynergy; all had multivessel disease and a tight stenosis in the vessel that supplied the abnormal segment. Exercise duration and time to $1 \mathrm{~mm}$ ST segment depression were significantly shorter in patients with a positive echocardiogram than in those without (both $p<0.01$ ). The sensitivity and specificity of dipyridamole stress echocardiography were $40 \%$ and $93 \%$ respectively; sensitivity improved to $60 \%$ when baseline $(n=18)$ or reversible asynergy defined an abnormal study (likelihood ratio = 9). Corresponding figures for stress electrocardiography were $38 \%$ and $80 \%$ for dipyridamole and $80 \%$ and $67 \%$ for exercise. Adverse reactions were seen in $67 \%$ of patients and included two instances of pronounced hypotension, one episode of prolonged myocardial ischaemia, and one cardiac arrest in a patient who was successfully resuscitated.

Conclusion-A positive high dose dipyridamole echocardiogram predicts multivessel disease and impaired coron- ary reserve, but low overall sensitivity and occasionally troublesome side effects limit its clinical usefulness.

Exercise echocardiography is an emerging technique for detection of coronary artery disease but it remains technically demanding and cannot be applied to patients unable or poorly motivated to exercise. ${ }^{1}$ Intravenous dipyridamole stress, which provokes aberrant distribution of flow in these patients, can allow myocardial perfusion defects to be visualised on thallium scintigraphy but this approach is expensive and requires facilities for nuclear medicine. ${ }^{2}$ Data from this centre on 21 patients with severe multivessel disease and a positive exercise electrocardiogram showed that dipyridamole provoked an echocardiographically detectable wall motion abnormality in only 11 patients. ${ }^{3}$ It has been suggested that this limited sensitivity $(52 \%)$ could be explained by the low dose of dipyridamole $(0.6 \mathrm{mg} / \mathrm{kg})$ and by the use of only the parasternal short axis projection, which made the test reliant on the adequacy of this single view for detection of transient asynergy. ${ }^{4}$ We therefore monitored a group of patients by means of high dose dipyridamole combined with four standard echocardiographic views. The aims of this prospective study were to establish the sensitivity and specificity of high dose dipyridamole stress echocardiography in the detection of coronary disease and to compare these results with dipyridamole stress and exercise electrocardiography, and to determine the safety and side effects of dipyridamole stress echocardiography.

\section{Patients and methods}

We screened 58 patients referred for coronary angiography for suspected coronary artery disease who satisfied the study enrolment criteria. Patients with cardiac failure, unstable angina, bronchospasm, left bundle branch block, or $\geqslant 1 \mathrm{~mm}$ of ST segment deviation from isoelectric on the baseline electrocardiogram were excluded. Stress echocardiography was not performed on three patients because of inadequate baseline endocardial definition on transthoracic imaging (test feasibility $95 \%$ ). The remaining 55 patients (41 men, mean age 55 (SD 9) (range 38-73) years) underwent dipyridamole stress echocardiography, exercise testing, and angiographic evaluation in random order (table 1). Coronary angiography showed normal coronary arteries in 15 and \\ Medicine (Clinical \\ Cardiology Unit) \\ Hospital and Royal \\ P Mazeik \\ P Nihoyannopoulos
}


Table 1 Clinical data and results of coronary angiography, exercise electrocardiography, dipyridamole stress electrocardiography, and dipyridamole stress echocardiography in 55 patients

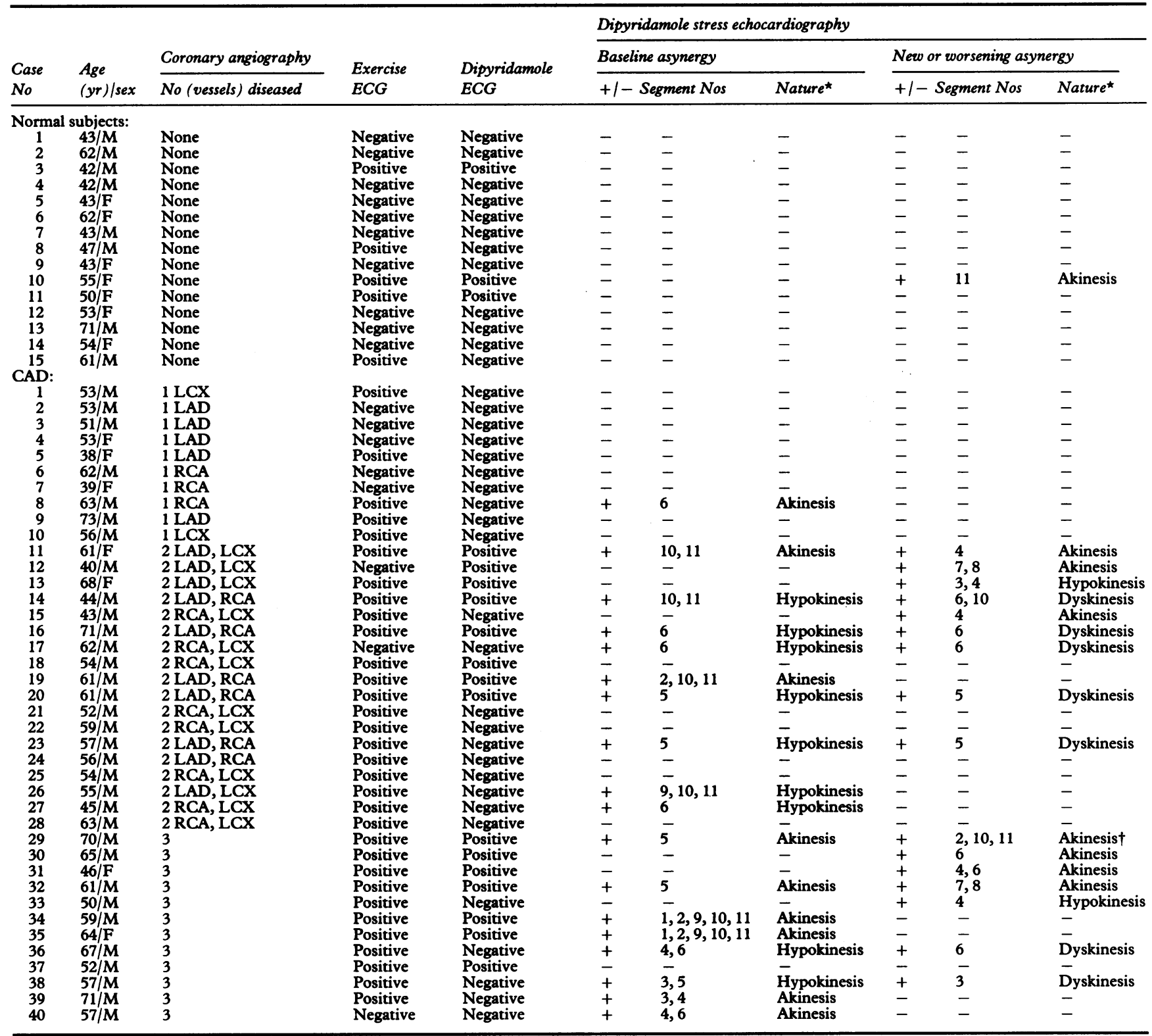

*The worst grade seen is stated; $\dagger$ associated with transient left ventricular cavity dilatation; ECG, electrocardiography; CAD, coronary artery disease; LAD, left anterior descending coronary artery; LCX, left circumflex coronary artery; RCA, right coronary artery.

single, double, and triple vessel disease in 10 , 18 , and 12 patients respectively. Antianginal treatment was stopped for four half lives before both the dipyridamole and exercise stress tests and patients were asked to avoid drinks containing caffeine on the day of the dipyridamole study. All patients gave informed consent and the study was approved by the hospital ethics committee.

\section{STUDY PROTOCOL}

After collection of baseline haemodynamic, electrocardiographic and cross sectional echocardiographic data, and with the patient under continuous electrocardiographic monitoring, dipyridamole $(0.6 \mathrm{mg} / \mathrm{kg})$ was infused intravenously over five minutes. After a five minute interval a further $0.4 \mathrm{mg} / \mathrm{kg}$ was infused over five minutes. The infusion was stopped if myocardial ischaemia or notable side effects occurred, and aminophylline was given if necessary. A 12 lead electrocardiogram was taken each minute with paediatric size electrodes to maximise the chest area available for echocardiography. Heart rate and blood pressure were recorded every one to two minutes by a Critikon Dinamap vital signs monitor. Cross sectional echocardiography (Toshiba SSH$160 \mathrm{~A}$ or $65 \mathrm{~A} 3.75 \mathrm{MHz}$ transducer) with the parasternal long and short axis (papillary muscle level) views and the apical four and two chamber views was continuous for up to 30 minutes after administration of dipyridamole. All studies were performed by one of us (JJ) and images were recorded on $12 \mathrm{~mm}$ VHS videotape for subsequent analysis. The time between coronary angiography and the dipyridamole study was 17 (SD 10) days; no significant cardiac events occurred during this period. 
EXERCISE ELECTROCARDIOGRAPHY

All patients had maximal modified Bruce treadmill exercise electrocardiography with a computerised ST segment analysis system (Case 12 , Marquette) ${ }^{5}$ and conventional end points. Both exercise stress and dipyridamole stress electrocardiograms were considered positive for ischaemia if there was $\geqslant 1 \mathrm{~mm}$ of new onset ST segment elevation or planar or downsloping ST segment depression $80 \mathrm{~ms}$ after the J point on three consecutive beats. The electrocardiograms were interpreted by an observer unaware of the other investigative findings. The interval between coronary angiography and exercise testing was $21(10)$ days during which no important cardiac events occurred.

\section{CARDIAC CATHETERISATION}

Coronary arteriography was carried out with a Philips Poly Diagnost $\mathrm{C}$ imaging system and used the Judkins' technique and multiple views. Coronary stenoses, evaluated qualitatively by a single experienced observer unaware of the other results, were considered significant when the diameter of a major epicardial vessel was reduced by $\geqslant 70 \%$.

IMAGE ANALYSIS

Cross sectional echocardiographic image analysis was performed blind from videotape playback by two independent experienced observers. Any disagreements were resolved by discussion. Wall motion was analysed by means of an 11 segment model of the left ventricle developed at the Hammersmith Hospital (figure); echocardiograms were read at baseline and peak stress and each segment was graded as normal or hyperkinetic, hypokinetic, akinetic, or dyskinetic. The development of a new abnormality of wall motion or worsening regional asynergy, defined as hypokinesis in any segment at baseline deteriorating to akinesis or

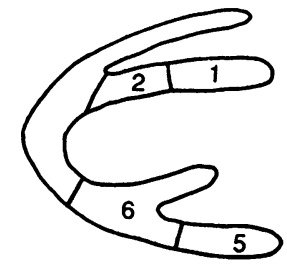

Parasternal long axis view

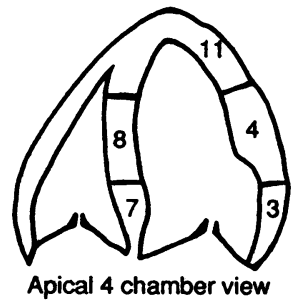

1 Basal, anteroseptal

2 Mid, anteroseptal

3 Basal, lateral

4 Mid, lateral

5 Basal, inferior

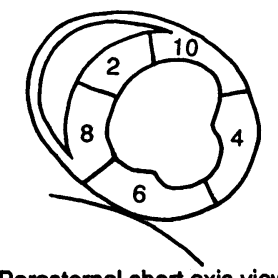

Parasternal short axis view (papillary muscle level)

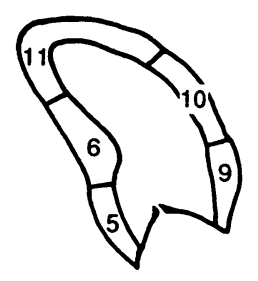

Apical 2 chamber view

6 Mid, inferior

7 Basal, posteroseptal

8 Mid, posteroseptal

9 Basal, anterior

10 Mid, anterior

11 Apical

Diagram of the Hammersmith Hospital 11 segment left ventricular model used for wall motion analysis. dyskinesis with dipyridamole stress, was regarded as an abnormal response.

\section{STATISTICAL ANALYSIS}

Continuous data are expressed as mean (SD). Paired or two sample $t$ tests were performed as necessary and group comparisons were by one way analysis of variance. The $\chi^{2}$ test with Yates' correction and McNemar's test were also used where appropriate. $p$ Values $<0.05$ were regarded as significant.

\section{Results}

HAEMODYNAMIC RESPONSE TO DIPYRIDAMOLE

The mean weight of the study population was 74 (12) $\mathrm{kg}$ and the mean dose of dipyridamole given was 63 (19) (range 20-101) mg. Table 2 shows the changes in haemodynamic variables by dipyridamole in patients with normal coronary arteries and in those with coronary disease; there were no significant differences in the haemodynamic response between these two groups. Similarly, no differences were found when patients with coronary disease and a wall motion abnormality at baseline $(n=18)$ were compared with those without $(n=22)$, and when patients with new or worsening transient asynergy $(n=16)$ were compared with those who showed a normal response $(n=24)$.

\section{WALL MOTION ANALYSIS}

Image quality during dipyridamole stress was adequate in the 55 subjects with satisfactory baseline studies. Transient hyperkinesis was the normal response to dipyridamole and this was particularly pronounced in the normally contracting segments of patients with a wall motion abnormality. Eighteen patients had asynergy at baseline. This involved one segment in eight, two segments in six, and three or more segments in four (table 1). New regional asynergy was seen in 11 patients and this was graded as akinesis in nine and hypokinesis in two; one patient with extensive akinesis in the area of the left anterior descending coronary artery and pronounced ST segment depression (9 $\mathrm{mm}$ in V5) also developed a transient dilated left ventricular cavity (table 1 ). Five of the 11 had two vessel disease, five had triple vessel disease, and one patient had normal coronary arteries and left ventricular hypertrophy secondary to essential hypertension. Transient dyskinesis of a segment hypokinetic at baseline developed in seven patients, and this was associated with remote new regional asynergy in one patient (table 1). All patients with coronary artery disease and a positive echocardiogram $(n=16)$ had a significant lesion in the vessel that supplied the abnormal segment. The sensitivity of dipyridamole stress echocardiography in one, two, and three vessel disease was $0 \%, 50 \%$, and $58 \%$ respectively compared with $0 \%, 44 \%$, and $58 \%$ for dipyridamole stress electrocardiography and $50 \%, 89 \%$, and $\mathbf{9 2} \%$ for exercise electrocardiography. When asynergy at baseline was added to reversible asynergy to define an abnormal study, overall sensitivity improved from $40 \%$ to $60 \%$ whereas specificity remained unchanged at $93 \%$ 
Table 2 Haemodynamic response to intravenous dipyridamole in patients with normal coronary arteries and with coronary artery disease

\begin{tabular}{|c|c|c|c|c|c|}
\hline & $\begin{array}{l}\text { Baseline } \\
\text { Mean (SD) }\end{array}$ & $\begin{array}{l}\text { Peak stress } \\
\text { Mean (SD) }\end{array}$ & $\begin{array}{l}\text { Mean } \\
\text { change }\end{array}$ & $\begin{array}{l}95 \% \text { CI of } \\
\text { mean change }\end{array}$ & p Value \\
\hline $\begin{array}{l}\text { Normal coronary arteries }(\mathrm{n}=15) \text { : } \\
\text { HR (beats } / \mathrm{min}) \\
\text { Systolic } \mathrm{BP}(\mathrm{mm} \mathrm{Hg}) \\
\text { Diastolic BP }(\mathrm{mm} \mathrm{Hg}) \\
\text { RPP }(\mathrm{mm} \mathrm{Hg} / \mathrm{min})\end{array}$ & $\begin{array}{l}70(14) \\
138(17) \\
84(8) \\
9776(2522)\end{array}$ & $\begin{array}{l}89(25) \\
134(22) \\
78(10) \\
12207(4417)\end{array}$ & $\begin{array}{l}19 \\
-4 \\
-6 \\
2431\end{array}$ & $\begin{array}{l}+8 \text { to } 29 \\
-18 \text { to } 9 \\
-12 \text { to } 1 \\
367 \text { to } 4496\end{array}$ & $\begin{array}{l}0.002 \\
\text { NS } \\
\text { NS } \\
0.02\end{array}$ \\
\hline $\begin{array}{l}\text { Coronary artery disease }(\mathrm{n}=40) \text { : } \\
\text { HR }(\text { beats } / \mathrm{min}) \\
\text { Systolic BP }(\mathrm{mm} \mathrm{Hg}) \\
\text { Diastolic BP }(\mathrm{mm} \mathrm{Hg}) \\
\text { RPP }(\mathrm{mm} \mathrm{Hg} / \mathrm{min})\end{array}$ & $\begin{array}{l}72(12) \\
141(21) \\
89(15) \\
10169(2493)\end{array}$ & $\begin{array}{l}91(13) \\
138(16) \\
86(10) \\
12532(2730)\end{array}$ & $\begin{array}{l}19 \\
-3 \\
-3 \\
2363\end{array}$ & $\begin{array}{l}+15 \text { to } 21 \\
-10 \text { to } 3 \\
-7 \text { to } 1 \\
1351 \text { to } 2838\end{array}$ & $\begin{array}{l}<0.001 \\
\text { NS } \\
\text { NS } \\
<0.001\end{array}$ \\
\hline
\end{tabular}

BP, blood pressure; $95 \% \mathrm{CI}, 95 \%$ confidence interval; HR, heart rate; RPP, rate-pressure product.

(likelihood ratio $=9$ ) (table 3 ). Visible collateral vessels at coronary angiography were present in 10 out of 16 patients $(63 \%)$ with inducible asynergy, and in 13 out of $24(54 \%)$ of the others. This difference was not significant. The observers agreed on wall motion analysis for 50 of 55 patients $(91 \%)$.

DIPYRIDAMOLE STRESS ELECTROCARDIOGRAPHY Significant ST segment depression had a sensitivity and specificity for coronary artery disease of $38 \%$ and $80 \%$ respectively (tables 1 and 3). Fifteen $(50 \%)$ of 30 patients with multivessel disease had a positive dipyridamole stress electrocardiogram. Of the 10 patients with coronary disease who showed new asynergy on echocardiography, eight had a positive electrocardiogram. The site of ST segment change, usually leads V5 or V6, was not strictly related to the site of the wall motion abnormality. Only three of seven patients with worsening regional asynergy had significant ST segment depression. The one patient with a falsely positive dypridamole echocardiogram also had positive electrocardiographic changes with both dipyridamole stress and exercise.

\section{EXERCISE TESTING}

The peak heart rate and rate-pressure product on exercise for the entire group was 138 (28) beats/min and $23121(6802) \mathrm{mm} \mathrm{Hg} / \mathrm{min}$ respectively. Table 3 shows the sensitivity and specificity of exercise electrocardiography. Nine of 10 coronary patients with new asynergy and six of seven with worsening asynergy had a positive exercise electrocardiogram (table 1). For patients with coronary artery disease, exercise duration in those with an abnormal echocardiographic response $(n=16)$ was 361 (146) seconds compared with 532 (177) seconds in the others $(n=24)(p<0.01)$. Similarly, time to $1 \mathrm{~mm}$ ST segent depression was 201 (192) seconds in patients with reversible asynergy $(n=14)$ compared with 479 (158) seconds in those with a negative response $(n=18)(p<0.01)$. Fourteen patients with coronary disease had significant ST segment deviation with both exercise and dipyridamole stress; the mean maximum extent of ST segment depression tended to be greater with exercise $(2.3(1.0) \mathrm{mm})$ than dipyridamole stress $(2 \cdot 0(2 \cdot 1) \mathrm{mm})$ but the difference was not significant.

\section{SIDE EFFECTS}

Table 4 documents the side effects experienced and treatment required after administration of dipyridamole. Chest pain developed in 13 of 16 $(81 \%)$ patients with coronary disease and dipyridamole induced asynergy compared with nine $(38 \%)$ of the other $24(p=0.02)$. One patient had prolonged ischaemia with severe chest pain for 30 minutes despite intravenous aminophylline (325 mg), but no evidence of myocardial infarction. Hypotension, defined as a fall in systolic blood pressure of $\geqslant 30 \mathrm{~mm} \mathrm{Hg}$ was seen in three cases. This was associated with sinus bradycardia in one patient and transient idioventricular rhythm in another. The third patient had an asystolic cardiac arrest preceded by chest pain and was promptly and succesfully resuscitated by treatment with aminophylline (200 $\mathrm{mg}$ ) and atropine $(1.2 \mathrm{mg})$.

\section{Discussion}

Some patients with suspected or definite coronary artery disease are unable to exercise because of peripheral vascular, orthopaedic, or neurological disease and others are poorly

Table 3 Comparative sensitivity, specificity, predictive value, and accuracy of dipyridamole stress echocardiography and dipyridamole stress and exercise electrocardiography

\begin{tabular}{llllll}
\hline & $\begin{array}{l}\text { Sensitivity } \\
(\%)\end{array}$ & $\begin{array}{l}\text { Specificity } \\
(\%)\end{array}$ & $\begin{array}{l}\text { Positive } \\
\text { predictive } \\
\text { value (\%) }\end{array}$ & $\begin{array}{l}\text { Negative } \\
\text { predictive } \\
\text { value (\%) }\end{array}$ & $\begin{array}{l}\text { Accuracy } \\
(\%)\end{array}$ \\
\hline $\begin{array}{l}\text { Dipyridamole echo: } \\
\text { New transient asynergy }\end{array}$ & $10 / 40(25)$ & $14 / 15(93)$ & $10 / 11(91)$ & $14 / 44(32)$ & $24 / 55(44)$ \\
New or worsening asynergy & $16 / 40(40)^{\star}$ & $14 / 15(93) \dagger$ & $16 / 17(94)$ & $14 / 38(37)$ & $30 / 55(55)$ \\
Baseline or new asynergy & $24 / 40(60)$ & $14 / 15(93)$ & $24 / 25(96)$ & $14 / 30(47)$ & $38 / 55(69)$ \\
Dipyridamole ECG & $15 / 40(38)$ & $12 / 15(80)$ & $15 / 18(83)$ & $12 / 37(32)$ & $27 / 55(49)$ \\
Exercise ECG & $32 / 40(80)$ & $10 / 15(67)$ & $32 / 37(86)$ & $10 / 18(56)$ & $42 / 55(76)$ \\
\hline
\end{tabular}

ECG, electrocardiography; echo, cross sectional echocardiography.

${ }^{\star} p<0.01 v$ exercise ECG; $+N S v$ exercise ECG. 
motivated to achieve a sufficient workload. ${ }^{6}$ Pharmacological stress induced by dipyridamole, combined with thallium scintigraphy or cross sectional echocardiography are alternative tests in such cases. ${ }^{6}$ Because echocardiography involves no exposure to radiation, is quicker and cheaper and, in general, more readily accessible than perfusion imaging we studied the utility and safety of this approach.

Dipyridamole blocks adenosine uptake into erythrocytes and endothelium, potentiating its dilatatory action on small vessels. ${ }^{4}$ This leads to a fall in perfusion pressure distal to coronary stenoses and flow redistribution from endocardium to epicardium causing perfusion defects to become visible on thallium scintigraphy or, if more severe, myocardial ischaemia and regional asynergy on echocardiography. ${ }^{4}$ The increase in rate-pressure product and fall in diastolic blood pressure (table 2 ) are probably less important. Haemodynamic variables changed similarly in all groups; perhaps a reflection of exaggerated hyperkinesis of the normally perfused myocardium in those patients with coronary disease.

Margonato et al at this centre used $0.6 \mathrm{mg} / \mathrm{kg}$ of dipyridamole to study 21 patients with multivessel disease and a positive exercise electrocardiogram. They found that only patients with severely limited coronary flow reserve and exercise capacity were likely to have a positive echocardiogram. The vessel where flow reserve was most impaired could be identified, however, despite the nonphysiological nature of the stress.

Picano et al found improved test sensitivity with high dose infusion of dipyridamole ${ }^{78}$ and we used this combined with multiple imaging views rather than a single projection as reported by Margonato et al. ${ }^{3}$ Fifteen patients with normal coronary arteries were also studied to obtain information on test specificity. Sixteen $(53 \%)$ of 30 patients with multivessel disease had new or worsening asynergy compared with $11(52 \%)$ of 21 patients studied by Margonato et al. ${ }^{3}$ Exercise duration and time to $1 \mathrm{~mm} \mathrm{ST}$ segment depression were significantly shorter in those with a positive echocardiogram, all of whom had a tight stenosis in the vessel that

Table 4 Side effects and treatment required after high dose dipyridamole stress in 55 patients

\begin{tabular}{lccc}
\hline & $\begin{array}{l}\text { CAD } \\
(n=40)\end{array}$ & $\begin{array}{l}\text { Normal } \\
(n=15)\end{array}$ & $\begin{array}{l}\text { Total } \\
(\%)\end{array}$ \\
\hline Side effect: & 22 & 5 & $27(49)$ \\
Chest pain & 7 & 10 & $17(31)$ \\
Headache & 5 & 4 & $9(16)$ \\
Dizziness & 5 & 0 & $5(9)$ \\
Dyspnoea & 3 & 2 & $5(9)$ \\
Nausea & 3 & 1 & $4(7)$ \\
Arrhythmia & 1 & 1 & $2(4)$ \\
Hypotension with syncope & 1 & 0 & $1(2)$ \\
Cardiac arrest & 1 & 0 & $1(2)$ \\
Vomiting & 26 & 11 & $37(67)$ \\
Total & & & \\
& & 1 & $10(18)$ \\
Treatment: & 9 & 0 & $3(5)$ \\
Aminophylline & 3 & 1 & $3(5)$ \\
Nitrates & 2 & 1 & $12(22)$ \\
Atropine & 11 & 1 & \\
Total & & &
\end{tabular}

$\mathrm{CAD}$, coronary artery disease. supplied the abnormal segment. The coronary reserve and angiographic severity of multivessel disease in these two studies were similar. We therefore cannot confirm that the use of high dose dipyridamole improves sensitivity.

None of the 10 patients with single vessel $\underline{T}$ disease had an abnormal stress echocar- $T$ diogram. This limitation has also been noted by Kern et al who were able to provoke new regional asynergy with intravenous dipyridamole in only three $(23 \%)$ of 13 patients with critical single vessel disease. ${ }^{9}$ Similarly Fung et al, who used dipyridamole stress to study open chest dogs with a severe coronary stenosis, found echocardiographically detectable dysfunction in only $55 \%$ of animals. ${ }^{10}$ i Dipyridamole stress echocardiography seems $\overrightarrow{0}$ less sensitive than dipyridamole stress thallium scintigraphy. ${ }^{311}$ A possible explanation is that small thallium defects, more likely in single vessel disease, may not be associated with an abnormality of wall motion. Also, apparent perfusion defects may only be relative because dipyridamole increases flow in the myocardium supplied by healthy vessels. Stress induced by intravenous adenosine infusion, which is limited by troublesome side effects at higher infusion rates, also seems more sensitive than echocardiography in the detection of coronary artery disease with perfusion imaging. ${ }^{12} 13$

Seven patients had worsening regional asynergy; in each case hypokinesis deteriorated to dyskinesis. Although a baseline wall motion abnormality was present in all seven, this was subtle in three instances and could easily have been overlooked. Whereas worsening asynergy is compatible with ischaemia of the remaining viable myocardium in an infarct zone, the change in regional loading induced by dipyridamole is a possible alternative explanation. Both mechanisms may contribute to different degrees in individual patients.

Dipyridamole administration in standard doses of $0.56 \mathrm{mg} / \mathrm{kg}$ seems to be relatively safe. ${ }^{14}$ Serious complications, including death, ${ }^{16}$ myocardial infarction, ${ }^{14}$ prolonged myocardial ischaemia, ${ }^{17}$ and cardiac arrest, ${ }^{1819}$ have been reported, though rarely. Information on the safety of higher doses is incomplete but, in our experience, side effects and severe reactions are more common. One of our patients who had three vessel disease developed prolonged myocardial ischaemia and another had an asystolic cardiac arrest that was preceded by chest pain and new regional asynergy which suggested an ischaemic basis. Two patients developed hypotension, bradycardia, and syncope. This may reflect adenosine induced depression of cardiac conduction tissue with peripheral vasodilation because one had normal coronary arteries and neither had evidence of preceding ischaemia. Both responded promptly to aminophylline and atropine. High dose dipyridamole may be more hazardous in elderly patients, who tolerate hypotension poorly and more frequently have occult disease of the conduction tissue. Only five of our patients were 70 or older.

The use of high dose dipyridamole stress during cross sectional echocardiography did 
not seem to improve diagnostic accuracy in coronary artery disease and resulted in more frequent, and occasionally severe, side effects. Further work is needed to determine whether digital echocardiographic techniques, which allow side by side comparison of wall segments before and after drug intervention, improve sensitivity. ${ }^{20}$

PM is a CORDA research fellow. We are grateful to CORDA, the heart charity, for financial support.

1 Sawada SG, Ryan T, Fineberg NS, et al. Exercise echocardiographic detection of coronary artery disease in women. $J$ Am Coll Cardiol 1989;14:1440-7.

2 Iskandrian AS, Heo J, Askenase A, Segal BL, Auerbach N. Dipyridamole cardiac imaging. Am Heart $J$ 1988; 115:432-43.

3 Margonato A, Chierchia S, Cianflone D, et al. Limitations of dipyridamole-echocardiography in effort angina pectoris. Am J Cardiol 1987;59:225-30.

4 Picano E. Dipyridamole-echocardiography test: historical background and physiologic basis. Eur Heart $J 1989$; background

5 Bruce RA, Kusumi F, Hosmer D. Maximal oxygen intake and nomographic assessment of functional aerobic impairment in cardiovascular disease. Am Heart $J$ 1973;85: $546-62$.

6 Stratmann HG, Kennedy HL. Evaluation of coronary artery disease in the patient unable to exercise: alternatives to exercise stress testing. Am Heart $J$ 1989;117:1344-65.

7 Picano E, Lattanzi F, Masini M, Distante A, L'Abbate A. Comparison of the high-dose dipyridamole-echocardiography test and exercise two-dimensional echocardiography for diagnosis of coronary artery disease. $\mathrm{Am} \mathrm{J}$ Cardiol 1987;59:539-42.

8 Picano E, Lattanzi F, Masini M, Distante A, L'Abbate A.
High-dose dipyridamole echocardiography test in effort angina pectoris. J Am Coll Cardiol 1986;8:846-54.

9 Kern MJ, Pearson AC, Labovitz AJ, et al. Effects of pharmacologic coronary hyperemia on echocardiographic pharmactricular function in patients with single vessel left ventricular function in patiente with single vessel coronary

10 Fung AY, Gallagher KP, Buda AJ. The physiologic basis of dobutamine as compared with dipyridamole stress interventions in the assessment of

11 Younis LT, Chaitman BR. Update on intravenous dipyridamole cardiac imaging in the assessment of ischaemic heart disease. Clin Cardiol 1990;13:3-10.

12 Verani MS, Mahmarian JJ, Hixson JB, Boyce TM, Staudacher RA. Diagnosis of coronary artery disease by controlled coronary vasodilation with adenosine and thallium-201 scintigraphy in patients unable to exercise. Circulation 1990;82:80-7.

13 Nguyen T, Heo J, Ogilby D, Hare T, Weber J, Iskandrian A. Adenosine-SPECT thallium-201 myocardial imaging [abstract]. J Am Coll Cardiol 1990;15:229A.

14 Ranhosky A, Kempthorne-Rawson J, and the Intravenous Dipyridamole Thallium Imaging Study Group. The safety of intravenous dipyridamole thallium myocardial perfusion imaging. Circulation 1990;81:205-9.

15 Homma S, Gilliland Y, Guiney TE, Strauss HW, Boucher CA. Safety of intravenous dipyridamole for stress testing CA. Safety of intravenous dipyridamole for stress testing
with thallium imaging. $A m J$ Cardiol $1987 ; 59: 152-4$.

16 Friedman HZ, Goldberg SF, Hauser AM, O'Neill WW. Death with dipyridamole-thallium imaging [letter]. $A n n$ (109:990-1.

17 Lewen MK, Labovitz AJ, Kern MJ, Chaitman BR Prolonged myocardial ischaemia after intravenou dipyridamole thallium imaging. Chest 1987;92:1102-4.

18 Bayliss J, Pearson M, Sutton GC. Ventricular dysrhythmias following intravenous dipyridamole during "stress" myocardial imaging. Br J Radiol 1983;56:686.

19 Blumenthal MS, McCauley CS. Cardiac arrest during dipyridamole imaging. Chest 1988;93:1103-4

20 Cohen JL, Greene TO, Alston JR, Wilchfort SD, Kim CS Usefulness of oral dipyridamole digital echocardiography for detecting coronary artery disease. Am J Cardiol $1989 ; 64: 385-6$. 